\title{
Therapeutic Effects of Plasmapheresis on Acute Exacerbations of Chronic Hepatitis B Infection
}

\author{
Yilmaz Bilgic $^{1}$, Sami Akbulut ${ }^{2}$, Ayse Cengiz ${ }^{3}$, Ahmet Sarici ${ }^{4}$, Yasir Cagin ${ }^{1}$, Murat Harputluoglu ${ }^{1}$ \\ 1. Gastroenterology and Hepatology, Inonu University, Malatya, TUR 2. Surgery/Liver Transplantation, Surgery and \\ Liver Transplant Institute, Inonu University Faculty of Medicine, Malatya, TUR 3. Internal Medicine, Inonu Univeristy, \\ Malatya, TUR 4. Hematology, Inonu University, Malatya, TUR
}

Corresponding author: Sami Akbulut, akbulutsami@gmail.com

\section{Abstract \\ Objective}

In this study, we aimed to demonstrate the effectiveness of plasmapheresis therapy in patients with acute exacerbation of chronic Hepatitis B (CHB) infection.

\section{Methods}

We selected 48 patients with acute exacerbation of CHB infection who were treated by plasmapheresis in our intensive care unit between 2009 and 2016. The patients' demographic characteristics and biochemical and hematological parameters, which were recorded before and after plasmapheresis, were assessed, and the effect of plasmapheresis on the course of patients' treatment was examined. The patients were also divided into three groups according to their clinical course (discharged: 24; transplanted: six; exitus: eight). The patients were further divided into four groups and compared based on the underlying causes that led to the exacerbation (spontaneous exacerbation: 25; caused by immunosuppressive drugs: nine; hepatotoxic drugs: six; other agents: eight).

\section{Results}

We observed significant improvements in terms of international normalized ratio (INR), aspartate aminotransferase (AST), alanine aminotransferase (ALT), gamma-glutamyl transferase (GGT), lactate dehydrogenase (LDH), total bilirubin, direct bilirubin, blood urea nitrogen (BUN), ammonia, and the Model for End-Stage Liver Disease (MELD) score after plasmapheresis therapy. However, there was no significant improvement in hemoglobin (Hb), white blood cell (WBC) count, platelets, albumin, and lactate values. Also, INR, ALP, and ALT values were found to be significantly correlated with transplants and exitus in patients.

\section{Conclusion}

Plasmapheresis therapy is a reliable treatment method that provides clinical recovery and improvement in laboratory parameters in patients with exacerbation of CHB infection.

Review began 12/27/2020 Review ended 01/13/2021 Published 01/19/2021

\section{(c) Copyright 2021}

Bilgic et al. This is an open access article distributed under the terms of the Creative Commons Attribution License CC-BY 4.0., which permits unrestricted use, distribution, and reproduction in any medium, provided the original author and source are credited.
Categories: Internal Medicine, Gastroenterology, Transplantation

Keywords: chronic hepatitis b, execarbation, plasmapheresis, liver transplantation

\section{Introduction}

Hepatitis B virus (HBV) is a partly double-stranded, hepatotropic virus that belongs to the orthohepadnavirus genome, and chronic hepatitis B (CHB) infection is a serious health problem globally [1]. $\mathrm{CHB}$ infection is a dynamic process and the progression of liver damage in patients depends on the age at which the infection occurs, the presence of viral replication, and the interaction between the virus and the host [2]. HBV-associated acute hepatitis may either be a true episode of acute hepatitis B infection or an acute exacerbation of previously unknown CHB infection. Acute exacerbation of hepatitis B infection is not common, and its cumulative incidence is estimated to be $10-30 \%$ per year.

Severe acute exacerbations may develop during the period of inactive hepatitis, although they mostly occur in the immunoclearance phase [3]. Acute hepatic exacerbations can occur due to a spontaneous exacerbation of immune response to HBV, exposure to immunosuppressive agents, or immunodeficiency; it can also result from a re-immune response to HBV following an interruption in the immunosuppressive treatment, alteration of the virus structure, the addition of other viruses such as the hepatitis C virus (HCV), hepatitis D virus (HDV), and human immunodeficiency virus (HIV), and alcohol or drug exposure that causes liver damage [4]. Acute exacerbations may be mild or severe with hepatic decompensation [5].

Extracorporeal liver support systems can be basically divided into three main categories: biological, non- 
biological (artificial), and bio-artificial (hybrid techniques) [6]. Non-biological liver support systems are further classified into the molecular adsorbent recirculating system, single-pass albumin dialysis, fractionated plasma separation and adsorption, and therapeutic plasma exchange (plasmapheresis) [7]. Plasmapheresis is one of the non-biological liver support systems, and it involves the process of removing the patient's plasma and replacing it with replacement fluids [8,9]. The purpose of therapeutic plasma exchange is to reduce the plasma components, which are known to be associated with the etiopathogenesis of a variety of diseases, thereby reducing the pathological damage to the organism or reversing this damage to some extent $[10,11]$. Examples of plasma proteins, which may be responsible for disease pathogenesis and are thought to be harmful to the patient, include monoclonal proteins, cryoglobulins, immunocomplexes, lipoproteins, autoantibodies, alloantibodies, and toxins [12].

Plasmapheresis involves the removal of plasmid from the body and replacing it with albumin or plasma $[13,14]$. It is a nonselective method that can remove harmful and toxic substances from blood circulation $[15,16]$. In general, plasma exchange is recommended three times a week for a few weeks if circulating immune complexes, myeloma proteins, and immunoglobulin G (IgG) and IgM type antibodies are intended to be removed. The plasma exchange time should be adjusted and gradually reduced by taking into account the laboratory data and the evolving clinical situation $[17,18]$. The primary aim of this study was to demonstrate the effectiveness of plasmapheresis therapy in patients with acute exacerbation of CHB infection.

\section{Materials And Methods}

For this study, we selected patients with acute exacerbation of CHB infection who were treated by plasmapheresis in the Department of Gastroenterohepatology, Inonu University Faculty of Medicine Intensive Care Unit between 2009 and 2016. Patients' demographic characteristics and biochemical parameters, which were recorded before and after plasmapheresis, were retrospectively evaluated to assess the effectiveness of plasmapheresis. Chronic HBV infection was defined as persistent seropositivity of hepatitis B surface antigen (HBsAg) during the entire follow-up period [19]. Acute exacerbation of CHB infection was defined as intermittent elevations of aminotransferase activity to more than 10 times the upper limit of normal and more than twice the baseline value [20]. As a result of the file scanning based on the above-mentioned criteria, a total of 62 patients were initially considered, but 14 patients were excluded from the study due to a lack of clarity regarding their demographic characteristics and biochemical data. Thus, a total of 48 patients were included in this study. Patients with conditions such as alcoholism, ischemia, pregnancy, and those with non-B hepatitis that caused similar biochemical profiles were excluded. Patients with other hepatotropic viruses were also excluded. Biochemical parameters of the patients were compared based on the following variables: timing of biochemical analysis (baseline vs. after 48 hours vs. last available), final status (exitus vs. transplanted vs. recovered), factors affecting exacerbation (spontaneous vs. hepatotoxic drugs vs. immunosuppressive drugs vs. other agents). The following clinical and biochemical parameters were analyzed: age in years, body mass index (BMI), hemoglobin ( $\mathrm{Hb})$, white blood cell (WBC), thrombocytes, aspartate aminotransferase (AST), alanine aminotransferase (ALT), lactate dehydrogenase (LDH), alkaline phosphatase (ALP), gamma-glutamyl transferase (GGT), total bilirubin, direct bilirubin, international normalized ratio (INR), albumin, ammonia, lactate, and the Model for End-Stage Liver Disease (MELD) score.

\section{Results}

A total of 48 patients who were aged between 18 and 70 years were included in this study; there were 34 male and 14 female patients. The median age of male and female patients was 47.7 years (range: 31-70

years) and 38.4 years (range: 18-49 years), respectively. The mean BMI of the patients was $22.8 \pm 4.7 \mathrm{~kg} / \mathrm{m}^{2}$, and the mean duration of HBV infection was $42.72 \pm 53.8$ months. The number of patients with known HBV history in the family was 21 (43.7\%), and the number of patients with or without a history of HBV in the family was 27 (56.25\%). There were six patients (12.5\%) with a history of alcohol use and 19 (39.6\%) patients with a smoking history. The number of patients with a history of hepatotoxic drug and herbal medicine use was two (1.6\%), and patients with immunosuppressive drug use constituted $6.4 \%$ of the cohort. However, the use of these drugs and herbal medicine had occurred long before they had led to the exacerbation, and had been abandoned.

Regarding the causes of acute exacerbations in patients, there were $25(52.1 \%)$ patients in the spontaneous group; while nine (18.7\%) patients had acquired it due to immunosuppressive drugs, it had been caused by hepatotoxic drugs in six (12.5\%) patients and the use of other agents in eight patients (16.7\%) [anti-tumor necrosis factor (anti-TNF) drugs: two; chemotherapy: four; rituximab: two]. The demographic data of the patients and the causes of exacerbation are presented in Table 1 . After the plasmapheresis treatment, significant amelioration was observed among patients in terms of INR $(p=0.001)$, AST $(p=0.027)$, ALT ( $\mathrm{p}=0.007)$, ALP ( $\mathrm{p}<0.001), \mathrm{GGT}(\mathrm{p}=0.001), \mathrm{LDH}(\mathrm{p}=0.001)$, total bilirubin $(\mathrm{p}=0.001)$, direct bilirubin $(\mathrm{p}=0.008)$, ammonia $(\mathrm{p}=0.05)$, and the MELD score $(\mathrm{p}=0.003)$. However, no significant changes were observed in $\mathrm{Hb}, \mathrm{WBC}$, thrombocytes, albumin, and lactate levels (Table 2). 


\section{Cureus}

Parameters

Gender

Male

Female

Factors causing the exacerbation of $\mathrm{CHBI}$

Group I (spontaneous)

Group II (hepatotoxic drug use)

Group III (immunosuppressive drug use)

While using immunosuppressive drugs

After using immunosuppressive drugs

Group IV (other drug use)

While using chemotherapeutics

While using anti-TNF-alpha

Rituximab
$\mathbf{N}$

29.9

$\%$

70.1

$25 \quad 52.1$

$6 \quad 12.5$

$9 \quad 18.7$

4

5

8

4

2

16.7

TABLE 1: Characteristics of patients with chronic hepatitis B infection exacerbation

CHBI: chronic hepatitis B infection; TNF-alpha: tumor necrosis factor-alpha 


\section{Cureus}

\begin{tabular}{|c|c|c|c|c|}
\hline Parameters & Baseline, median (min-max) & After 48 hours, median (min-max) & Last available, median (min-max) & P-value \\
\hline $\mathrm{Hb}, \mathrm{g} / \mathrm{dL}$ & $10.8(6.7-15.9)$ & $10.2(6.4-14.7)$ & $10.5(6.9-15.2)$ & 0.073 \\
\hline WBC, $\times 10 E^{3} / \mathrm{uL}$ & $9.1(2.4-28.1)$ & $9.6(2.6-28.5)$ & $9.4(1.6-29.1)$ & 0.060 \\
\hline Thrombocytes, x 109/L & $112(43-354)$ & $106(41-311)$ & $104(27-298)$ & 0.820 \\
\hline INR & $2.6(1-4.3)$ & $1.1(0.9-3.3)$ & $1.1(1-3.5)$ & $<0.001$ \\
\hline AST, IU/L & $372(54-6,404)$ & $272(38-5,624)$ & $231(32-3,151)$ & 0.027 \\
\hline ALT, IU/L & $449(75-5,765)$ & $384(68-4,032)$ & $283(27-2,543)$ & 0.007 \\
\hline ALP, IU/L & $172(30-732)$ & $152(34-528)$ & $139(11-352)$ & $<0.001$ \\
\hline GGT, IU/L & $197(38-597)$ & $149(32-502)$ & $152(33-484)$ & 0.001 \\
\hline LDH, IU/L & $426(119-1,007)$ & $321(86-752)$ & $364(145-1,200)$ & 0.001 \\
\hline Total bilirubin, mg/dL & $16.4(14.5-37.9)$ & $12(9.8-24.7)$ & $13(3.8-30.3)$ & 0.001 \\
\hline Direct bilirubin, mg/dL & $10.2(2.1-25.9)$ & $8.3(1.6-16.2)$ & $7.9(1.5-21.6)$ & 0.008 \\
\hline Albumin, g/dL & $2.85(2.1-3.8)$ & $2.9(2.4-3.8)$ & $2.86(1.8-3.9)$ & 0.550 \\
\hline Ammonia, mcg/dL & $135(58-465)$ & $27.4(47-387)$ & $30.4(47-227)$ & 0.050 \\
\hline Lactate, $\mathrm{mmol} / \mathrm{l}$ & $21.3(8.3-120)$ & $21.2(8.1-115)$ & $21.5(5.4-71.6)$ & 0.416 \\
\hline MELD score & $15(10-32)$ & $12(9-26)$ & $10(8-21)$ & 0.003 \\
\hline
\end{tabular}

\section{TABLE 2: Laboratory effects of plasmapheresis on patients with chronic hepatitis B infection}

exacerbation

Hb: hemoglobin; WBC: white blood cells; INR: international normalized ratio; AST: aspartate aminotransferase; ALT: alanine aminotransferase; LDH: lactate dehydrogenase; ALP: alkaline phosphatase; GGT: gamma-glutamyl transferase; MELD: Model for End-Stage Liver Disease

Patients were divided into three groups in terms of final status: those who were deceased $(n=8)$, those who were transplanted $(\mathrm{n}=16)$, and those who recovered $(\mathrm{n}=24)$. There were statistically significant differences between deceased and recovered groups in terms of creatinine ( $\mathrm{p}=0.018), \mathrm{Hb}(\mathrm{p}<0.001)$, thrombocytes $(\mathrm{p}=0.001)$, INR $(\mathrm{p}=0.001)$, GGT $(\mathrm{p}=0.015)$, AST $(\mathrm{p}=0.018)$, ALT $(\mathrm{p}=0.014)$, lactate $(\mathrm{p}<0.001)$, and the MELD score $(\mathrm{p}=0.01)$. Also, there were statistically significant differences between transplanted and deceased groups in terms of $\mathrm{Hb}(\mathrm{p}=0.018)$, thrombocytes $(\mathrm{p}=0.006)$, INR ( $\mathrm{p}=0.002)$, ALP ( $\mathrm{p}=0.002)$, ALT $(\mathrm{p}=0.007)$, lactate $(\mathrm{p}=0.001)$, and ammonia levels $(\mathrm{p}=0.013)$. Morever, there were statistically significant differences between the recovered and and transplanted groups in creatinine $(\mathrm{p}=0.016)$, ALP $(\mathrm{p}=0.001), \mathrm{GGT}(\mathrm{p}=0.001)$, AST ( $\mathrm{p}=0.036)$, direct bilirubin $(\mathrm{p}=0.043)$, and the MELD score $(\mathrm{p}=0.01)$ (Table 3). 


\section{Cureus}

\begin{tabular}{|c|c|c|c|c|}
\hline Parameters & $\begin{array}{l}\text { Deceased ( } n=8) \text {, median (min- } \\
\text { max) }\end{array}$ & $\begin{array}{l}\text { Transplanted ( } n=16 \text { ), median (min- } \\
\text { max) }\end{array}$ & $\begin{array}{l}\text { Recovered }(\mathrm{n}=24) \text {, median (min- } \\
\text { max) }\end{array}$ & P-value \\
\hline Age, years & 48 (32-70) & $45(29-58)$ & $37(18-54)$ & 0.146 \\
\hline Creatinine, mg/al & $1.4(0.5-2.1)$ & $1.2(0.7-2.4)$ & $0.5(0.3-1.0)$ & $0.018^{\star} / 0.016^{+}$ \\
\hline $\mathrm{Hb}, \mathrm{g} / \mathrm{dL}$ & $9.5(6.7-12.7)$ & $10.4(7.9-12.9)$ & $11.1(10.1-15.9)$ & $<0.001^{\star} / 0.018^{\beta}$ \\
\hline WBC, $\times 10 E^{3} / \mathrm{uL}$ & $9.4(3.2-28.5)$ & $9.7(1.6-21.4)$ & $9.2(2.4-22.7)$ & 0.189 \\
\hline $\begin{array}{l}\text { Thrombocytes, } x \\
10^{9} / \mathrm{L}\end{array}$ & $125(43-324)$ & $144(87-226)$ & $152(75-354)$ & $0.001^{\star} / 0.006^{\beta}$ \\
\hline INR & $2.6(1.7-4.3)$ & $2.4(1.8-3.7)$ & $1.84(1-3.2)$ & $0.001^{\star} / 0.002^{\beta}$ \\
\hline AST, IU/L & $586(116-6,404)$ & $485(154-5,418)$ & $341(54-4,267)$ & $0.018^{\star} / 0.036^{+}$ \\
\hline ALT, IU/L & $486(75-5,765)$ & $470(91-5,456)$ & $428(89-5,216)$ & $0.007^{\beta} / 0.014^{*}$ \\
\hline ALP, IU/L & $224(30-732)$ & $251(56-554)$ & $188(77-356)$ & $0.001^{+} / 0.002^{\beta}$ \\
\hline GGT, IU/L & $224(44-514)$ & $251(87-597)$ & $203(72-472)$ & $0.001^{+} / 0.015^{\star}$ \\
\hline $\mathrm{LDH}, \mathrm{IU} / \mathrm{L}$ & $544(256-1,007)$ & $579(287-946)$ & 412 (119-786) & 0.960 \\
\hline $\begin{array}{l}\text { Total } \\
\text { bilirubin, } \mathrm{mg} / \mathrm{dL}\end{array}$ & $18.4(14.5-37.9)$ & $15.4(12.7-28.7)$ & $12.2(14.8-24.7)$ & 0.590 \\
\hline $\begin{array}{l}\text { Direct } \\
\text { bilirubin, mg/dL }\end{array}$ & $14.2(10.1-25.4)$ & $10.1(8.8-25.9)$ & $8.7(2.1-18.9)$ & $0.043^{+}$ \\
\hline Albumin, g/dL & $2.3(2-3.2)$ & $2.4(2.2-3.3)$ & $2.9(2.6-3.8)$ & 0.850 \\
\hline Ammonia, mcg/dL & $138(58-384)$ & $132(72-455)$ & $132(63-465)$ & $0.013^{\beta}$ \\
\hline Lactate, $\mathrm{mmol} / \mathrm{l}$ & $23.5(14.4-120)$ & $22.8(15-112)$ & $20.8(8.3-110)$ & $<0.001^{\star} / 0.01^{+}$ \\
\hline MELD score & $18(16-30)$ & $19(16-32)$ & $14(10-21)$ & $0.01^{\star} / 0.01^{+}$ \\
\hline
\end{tabular}

\section{TABLE 3: Comparison of the biochemical analysis of deceased, transplanted, and recovered}

patients who received plasmapheresis

*Significant difference between recovered and deceased; ${ }^{\beta}$ significant difference between transplanted and deceased; ${ }^{+}$significant difference between recovered and transplanted

$\mathrm{Hb}$ : hemoglobin; WBC: white blood cells; INR: international normalized ratio; AST: aspartate aminotransferase; ALT: alanine aminotransferase; LDH: lactate dehydrogenase; ALP: alkaline phosphatase; GGT: gamma-glutamyl transferase; MELD: Model for End-Stage Liver Disease

Patients were divided into four groups based on the factors causing the exacerbation of CHBI. Statistical analysis was performed to determine whether plasmapheresis was effective among these groups (spontaneous exacerbation and other drug groups), and there was a statistically significant difference in terms of total bilirubin $(\mathrm{p}=0.04)$ and direct bilirubin $(\mathrm{p}=0.03)$ values (Table 4$)$. 


\section{Cureus}

\begin{tabular}{|c|c|c|c|c|c|}
\hline Parameters & $\begin{array}{l}\text { Spontaneous, median } \\
\text { (min-max) }\end{array}$ & $\begin{array}{l}\text { Hepatotoxic } \\
\text { drugs, median (min-max) }\end{array}$ & $\begin{array}{l}\text { Immunosuppressive } \\
\text { agents, median (min-max) }\end{array}$ & $\begin{array}{l}\text { Other drugs, median } \\
\text { (min-max) }\end{array}$ & $\begin{array}{l}\text { P- } \\
\text { value }\end{array}$ \\
\hline INR & $2.1(1.3-3)$ & $3.2(1.2-4.3)$ & $2.9(1.8-3.2)$ & $3.2(1-3.7)$ & 0.320 \\
\hline AST, IU/L & $498(116-771)$ & $1,593(228-6,404)$ & $1,023(245-1,412)$ & $544(229-654)$ & 0.570 \\
\hline LDH, IU/L & $486(354-624)$ & $863(119-1,007)$ & $616(321-745)$ & $631(358-958)$ & 0.280 \\
\hline $\begin{array}{l}\text { Total } \\
\text { bilirubin, } \mathrm{mg} / \mathrm{dL}\end{array}$ & $18(12.7-25.8)$ & $18.4(12.4-22.1)$ & $19(12.4-24.7)$ & $29.6(24.7-37.9)$ & 0.040 \\
\hline $\begin{array}{l}\text { Direct } \\
\text { bilirubin, } \mathrm{mg} / \mathrm{dL}\end{array}$ & $12(2.1-18.9)$ & $12(3.1-16.5)$ & $12.5(3.2-20.4)$ & $20.3(18.7-25.9)$ & 0.030 \\
\hline Albumin, g/dL & $2.86(2.6-3.8)$ & $2.85(2.4-3.5)$ & $2.73(2.6-2.9)$ & $2.36(2.0-2.7)$ & 0.080 \\
\hline Ammonia, mcg/dL & $120(62-157)$ & $240(178-465)$ & $183(94-214)$ & $118(58-144)$ & 0.620 \\
\hline
\end{tabular}

TABLE 4: Comparison of the efficacy of the plasmapheresis between groups created based on underlying causes

INR: international normalized ratio; AST: aspartate aminotransferase; LDH: lactate dehydrogenase

\section{Discussion}

There is a dynamic process in CHB infection. In other words, while it may continue to be asymptomatic in patients, it can also be associated with a course that leads to fulminant hepatitis. Viral infections, interstitial toxic drugs used for other reasons, the age at which the patient was exposed to the virus, changes in the genetic structure of the virus, and the use of immunosuppressive drugs or the development of another immunosuppressive condition can affect the duration of the virus infection. Cytokines occur as a result of various stimuli in CHB exacerbations. The removal of these cytokines in the dynamic process of CHB exacerbation process can reduce cytokine damage to the liver and contribute to the development of balance in the body. Various treatments are performed in this patient group. One of these treatment methods is called plasmapheresis. Plasmapheresis is classified as indication category III by the American Association of Blood Banks (AABB) [21,22]. In this study, we aimed to demonstrate the effectiveness of plasmapheresis on laboratory and clinical parameters in patients with acute HBV exacerbation.

A moderate increase in hyperbilirubinemia, ALP, and transaminase levels may be observed in this condition. High liver enzymes are a component of the hemolysis, elevated liver enzymes, low platelet count (HELLP) syndrome. Elevated liver enzymes are believed to be caused by the slowing of the secondary blood flow to fibrin deposits in the hepatic sinusoids [23]. Both experimental and clinical studies have shown that there is a significant decrease thanks to plasmapheresis in TNF-alpha, interleukin-6 (IL-6), and endotoxins levels, which play a role in the pathogenesis of systemic inflammatory response syndrome (SIRS) and sepsis [24,25]. AST and GGT are liver enzymes showing cell destruction, and in our study group, plasmapheresis significantly improved these two laboratory values. However, as shown in many studies, the improvement in AST and GGT values did not correlate with improvements in liver histology [26].

In a study by Tsai et al. [27], high AST and bilirubin levels, low albumin and platelet levels, and prolonged prothrombin time (PT) were reported as prognostic factors of acute exacerbations of CHB. A study examining the effects of plasmapheresis and hemodiafiltration separately and in combination with cytokines has revealed that a single plasmapheresis treatment significantly managed to reduced IL-6 and bilirubin levels but no significant changes in TNF-alpha and IL-8 levels were observed [28].

In a study of acute liver failure patients, it was shown that plasmapheresis provides a significant decrease in ammonia levels [29]. Another study has reported that in patients with newborn hyperbilirubinemia, bilirubin levels were significantly reduced by plasmapheresis treatment [30]. In our study, after the plasmapheresis treatment, there was significant amelioration in INR, AST, ALT, ALP, GGT, LDH, total bilirubin, direct bilirubin, ammonia, and the MELD score. However, no significant changes were observed in Hb, WBC, platelets, albumin, and lactate levels.

We believe that the therapeutic effect of plasmapheresis is more effective in acute exacerbation of CHB that occurs as spontaneous events and in immunosuppressive patients compared to other exacerbations. We also hold the view that plasmapheresis may improve laboratory values and clinical course in acute exacerbation of hepatitis B and may serve as a bridge, especially in patients waiting for liver transplantation. Eight of the 48 patients in our study had died, 16 of them had been transplanted, and 24 of them were discharged. It is 
also necessary to consider the factors accompanying CHB that cause mortality in patients who are followed up in the intensive care. Immunosuppressant use, anti-TNF use, and chemotherapeutic treatments cause acute exacerbations in $\mathrm{CHB}$, as well as suppressing the immune system and making the patient vulnerable to other infections. While acute exacerbations of CHB already have a picture similar to that of SIRS, hospital infections added to it accelerate this process and lead the patient to a process that results in septic shock and thereby increase mortality. Therefore, these factors are also likely to have constituted a basis for the illness among the patients who had died in our cohort. There are no studies in the literature related to this subject; hence, additional studies are warranted so that more light is shed on this topic. Similarly, additional factors such as diabetes mellitus, metabolic factors such as obesity, persistent activation of liver disease, frequent exacerbations, high geographic endemicity, the genotype of the virus, and pre-core or core promoter variants also affect the natural course of $\mathrm{CHB}$ and alter the response to plasmapheresis. Further studies are therefore required, including those involving more cases and factors that affect the natural course of $\mathrm{CHB}$.

Our patients were divided into three groups: those who died, transferred, and recovered, respectively. There was a statistically significant difference between the excluded group and the recovered group in terms of creatinine, $\mathrm{Hb}$, thrombocytes, INR, GGT, AST, ALT, lactate, and the MELD score, and, additionally, there was a statistically significant difference between the transplanted group and the excluded group in terms of $\mathrm{Hb}$, thrombocyte, INR, ALP, ALT, lactate, and ammonia; moreover, there was a statistically significant difference between the recovery group and the transplanted group pertaining to creatinine, ALP, GGT, AST, direct bilirubin, and the MELD score.

Based on our findings, changes in biochemical parameters contribute to mortality in CHB exacerbations. Biochemical, hematologic, and MELD score changes with plasmapheresis may have a positive effect on survival in these patient groups. In our study, patients were further divided into four groups in order to investigate whether there was any difference in the effectiveness of plasmapheresis based on the different etiologic agents that had caused the exacerbation of the CHB infection. The statistical analysis that determined the efficacy of plasmapheresis among these groups showed a significant association between the spontaneous exacerbation group and the other-drug groups only in total bilirubin and direct bilirubin. That is, in the spontaneous CHB exacerbation group, total and direct bilirubin values decreased with plasmapheresis treatment compared to the other groups. This has led us to believe that this treatment method may be more beneficial in this group of patients. However, further randomized prospective controlled studies involving larger groups of patients are needed to arrive at a comprehensive and definitive understanding of this subject.

\section{Conclusions}

In conclusion, there are no other studies in the literature similar to our current study, and the results of this study have shown that plasmapheresis is an effective treatment modality for patients with acute exacerbation of $\mathrm{CHB}$ infection.

\section{Additional Information}

\section{Disclosures}

Human subjects: Consent was obtained or waived by all participants in this study. Animal subjects: All authors have confirmed that this study did not involve animal subjects or tissue. Conflicts of interest: In compliance with the ICMJE uniform disclosure form, all authors declare the following: Payment/services info: All authors have declared that no financial support was received from any organization for the submitted work. Financial relationships: All authors have declared that they have no financial relationships at present or within the previous three years with any organizations that might have an interest in the submitted work. Other relationships: All authors have declared that there are no other relationships or activities that could appear to have influenced the submitted work.

\section{References}

1. Lamontagne RJ, Bagga S, Bouchard MJ: Hepatitis B virus molecular biology and pathogenesis . Hepatoma Res. 2016, 2:163-86. 10.20517/2394-5079.2016.05

2. Liang TJ: Hepatitis B: the virus and disease. Hepatology. 2009, 49:S13-21. 10.1002/hep.22881

3. Mochida S, Nakayama N, Ido A, et al.: Revised criteria for classification of the etiologies of acute liver failure and late-onset hepatic failure in Japan: A report by the Intractable Hepato-biliary Diseases Study Group of Japan in 2015. Hepatol Res. 2016, 46:369-71. 10.1111/hepr.12626

4. Puri P: Acute exacerbation of chronic hepatitis B: the dilemma of differentiation from acute viral hepatitis B. J Clin Exp Hepatol. 2013, 3:301-12. 10.1016/j.jceh.2013.08.014

5. Tsai WL, Sun WC, Cheng JS: Chronic hepatitis B with spontaneous severe acute exacerbation . Int J Mol Sci. 2015, 16:28126-45. 10.3390/ijms161226087

6. Laleman W, Wilmer A, Evenepoel P, Verslype C, Fevery J, Nevens F: Review article: non-biological liver support in liver failure. Aliment Pharmacol Ther. 2006, 23:351-63. 10.1111/j.1365-2036.2006.02765.x

7. Podoll AS, DeGolovine A, Finkel KW: Liver support systems---a review . ASAIO J. 2012, 58:443-9. 10.1097/MAT.0b013e31825f3446

8. van de Kerkhove MP, Hoekstra R, Chamuleau RA, van Gulik TM: Clinical application of bioartificial liver 
support systems. Ann Surg. 2004, 240:216-30. 10.1097/01.sla.0000132986.75257.19

9. Tan EX, Wang MX, Pang J, Lee GH: Plasma exchange in patients with acute and acute-on-chronic liver failure: a systematic review. World J Gastroenterol. 2020, 26:219-45. 10.3748/wjg.v26.i2.219

10. Rozga J: Liver support technology--an update. Xenotransplantation. 2006, 13:380-9. 10.1111/j.13993089.2006.00323.x

11. Akdogan M, Camci C, Gurakar A, et al.: The effect of total plasma exchange on fulminant hepatic failure . J Clin Apher. 2006, 21:96-9. 10.1002/jca.20064

12. Li M, Sun J, Li J, et al.: Clinical observation on the treatment of acute liver failure by combined nonbiological artificial liver. Exp Ther Med. 2016, 12:3873-6. 10.3892/etm.2016.3887

13. Li M, Wang Z, Wang Y, Du C, Li S, Shi Z, Lu B: Part of plasmapheresis with plasma filtration adsorption combined with continuous hemodiafiltration in the treatment of severe acute liver failure. Exp Ther Med. 2016, $12: 2582-4.10 .3892 /$ etm.2016.3633

14. Hadem J, Hafer C, Schneider AS, et al.: Therapeutic plasma exchange as rescue therapy in severe sepsis and septic shock: retrospective observational single-centre study of 23 patients. BMC Anesthesiol. 2014, 14:24. 10.1186/1471-2253-14-24

15. Kandiah PA, Olson JC, Subramanian RM: Emerging strategies for the treatment of patients with acute hepatic failure. Curr Opin Crit Care. 2016, 22:142-51. 10.1097/MCC.0000000000000291

16. Bektas M, Idilman R, Soykan I, et al.: Adjuvant therapeutic plasma exchange in liver failure: assessments of clinical and laboratory parameters. J Clin Gastroenterol. 2008, 42:517-21. 10.1097/MCG.0b013e31815878ff

17. Rimmer E, Houston BL, Kumar A, et al.: The efficacy and safety of plasma exchange in patients with sepsis and septic shock: a systematic review and meta-analysis. Crit Care. 2014, 18:699. 10.1186/s13054-014-06992

18. Mohta S, Soneja M, Vyas S, Khot W: Tuberculosis and Guillain-Barre syndrome: a chance association? Intractable Rare Dis Res. 2017, 6:55-7. 10.5582/irdr.2016.01073

19. Kao JH, Chen PJ, Lai MY, Chen DS: Acute exacerbations of chronic hepatitis B are rarely associated with superinfection of hepatitis B virus. Hepatology. 2001, 34:817-23. 10.1053/jhep.2001.28188

20. Chang ML, Liaw YF: Hepatitis B flares in chronic hepatitis B: pathogenesis, natural course, and management. J Hepatol. 2014, 61:1407-17. 10.1016/j.jhep.2014.08.033

21. Smith JW, Weinstein R, Hillyer KL; AABB Hemapheresis Committee; American Society for Apheresis: Therapeutic apheresis: a summary of current indication categories endorsed by the AABB and the American Society for Apheresis. Transfusion. 2003, 43:820-2. 10.1046/j.1537-2995.2003.00397.x

22. Harry R, Auzinger G, Wendon J: The clinical importance of adrenal insufficiency in acute hepatic dysfunction. Hepatology. 2002, 36:395-402. 10.1053/jhep.2002.34514

23. Padden MO: HELLP syndrome: recognition and perinatal management. Am Fam Physician. 1999, 60:829-36.

24. Iwai H, Nagaki M, Naito T, et al.: Removal of endotoxin and cytokines by plasma exchange in patients with acute hepatic failure. Crit Care Med. 1998, 26:873-6. 10.1097/00003246-199805000-00021

25. van Deuren M, Frieling JT, van der Ven-Jongekrijg J, et al.: Plasma patterns of tumor necrosis factor-alpha (TNF) and TNF soluble receptors during acute meningococcal infections and the effect of plasma exchange. Clin Infect Dis. 1998, 26:918-23. 10.1086/513933

26. Barton JR, Riely CA, Adamec TA, Shanklin DR, Khoury AD, Sibai BM: Hepatic histopathologic condition does not correlate with laboratory abnormalities in HELLP syndrome (hemolysis, elevated liver enzymes, and low platelet count). Am J Obstet Gynecol. 1992, 167:1538-43. 10.1016/0002-9378(92)91735-s

27. Tsai WL, Lo GH, Hsu PI, et al.: Role of genotype and precore/basal core promoter mutations of hepatitis B virus in patients with chronic hepatitis B with acute exacerbation. Scand J Gastroenterol. 2008, 43:196-201. 10.1080/00365520701745693

28. Nakae H, Asanuma Y, Tajimi K: Cytokine removal by plasma exchange with continuous hemodiafiltration in critically ill patients. Ther Apher. 2002, 6:419-24. 10.1046/j.1526-0968.2002.00464.x

29. Clemmesen JO, Kondrup J, Nielsen LB, Larsen FS, Ott P: Effects of high-volume plasmapheresis on ammonia, urea, and amino acids in patients with acute liver failure. Am J Gastroenterol. 2001, 96:1217-23. 10.1111/j.1572-0241.2001.03706.x

30. Bambauer R, el-Saadi R, Graf N, Jesberger HJ, Limbach HG, Cordes H: Plasmapheresis in newborns with hyperbilirubinemia. Artif Organs. 1992, 16:472-6. 10.1111/j.1525-1594.1992.tb00326.x 